\title{
СТРУКТУРА ЭНДОКРИННОЙ ПАТОЛОГИИ СРЕДИ ДЕТЕЙ АРКТИЧЕСКИХ РАЙОНОВ РЕСПУБЛИКИ САХА (ЯКУТИЯ)
}

\author{
Н.А. Данилов', М.Е. Никифорова ${ }^{2}$, Т.Е. Бурцева ${ }^{3}$ \\ 'ГБУРС(Я) «Якутская городская больница №2» \\ 2ГАУ РС(Я) «Республиканская больница №1 - Начиональный чентр медичины» \\ ${ }^{3}$ ФГБНУ «Якутский научный центр комплексных медицинских проблем»
}

АКТУАЛЬНОСТЬ. Эндокринологические заболевания являются весьма распространенными среди детской популяции в России. Наиболее часто встречающимися из них являются избыточная масса тела, ожирение, заболевания щитовидной железы, вызванные дефицитом йода. Особый интерес представляет распространенность эндокринной патологии среди детей, проживающих в арктических регионах, поскольку их отдаленное расположение, отсутствие специалистов на местах и образ жизни, проживающих там детей привносят свои коррективы в развитие, распространенность, диагностику и лечение данных заболеваний.

ЦЕЛЬ: изучить структуру эндокринной патологии среди детей арктического региона России Caxa.

МАТЕРИАЛЫ И МЕТОДЫ. В РамкаХ выездНЫХ командировок врачей-специалистов детским эндокринологом были осмотрены дети возрастом от 2 до 17 лет из Булунского и Жиганского муниципальных районов Республики Саха (Якутия). В общем числе было осмотрено 547 детей различных возрастов.

РЕЗУЛЬТАТЫ. По Булунскому району было осмотрено 272 ребенка, из которых 170 мальчиков и 102 девочки, у 61 ребенка была выявлена эндокринологическая патология, из которых 32 случая - избыточная масса тела и ожирение; 17 случаев эндемического зоба; 6 случаев низкорослости; 2 случая сахарного диабета 1 типа (выявлен ранее); 3 случая задержки полового развития. По Жиганскому району было осмотрено 275 детей, из которых 147 девочек, 128 мальчиков. Эндокринная патология была выявлена у 35 детей. Из них: избыточная масса тела и ожирение 31 случай; 6 случаев эндемического зоба; 4 случая низкорослости; 1 случай преждевременного полового развития; 1 случай высокорослости.

Как показывают результаты медицинских осмотров, распределение эндокринологической патологии в данных районах в целом соответствует тому, которое имеет место в среднем по Российской Федерации. Наиболее часто встречающейся патологией является избыточная масса тела и ожирение - $65.63 \%$ от общего числа выявленной эндокринной патологии, на втором месте идет эндемический зоб - 23.96\%, низкорослость была выявлена в $10.42 \%$ случаев, задержка полового развития имеет место у $3.13 \%$ обследованных детей.

Выводы.

1. Практически каждый пятый ребенок из числа обследованных имеет эндокринную патологию.

2. Большую часть эндокринной патологии составляет избыточная масса тела и ожирение.

3. Высокая распространенность эндемического зоба является ожидаемой в йододефицитном регионе.

4. Низкорослость и задержка полового развития, вероятно, связаны с конституциональными и этническими особенностями проживающего в данных районах населения. 